\title{
Is asbestos or asbestosis the cause of the increased risk of lung cancer in asbestos workers?
}

"Does silica or asbestos or the fibrosis of the lung they produce tend to inhibit cancer of the lung or to produce it? If the latter, do either of these two substances act as specific carcinogenic agents like tar, or is it that the disease they produce only prepares the soil for the occurrence of cancer?... With asbestosis, among 103 fatal cases in which asbestosis or asbestosis with tuberculosis was present, cancer of the lung was associated in 12 cases (11.6\%)."

This quotation from the 1938 report of the Chief Inspector of Factories (written by Merewether) posed a question which, in the case of asbestos, has still not been settled. Ten years later, Merewether reported that $17 \%$ of deaths in workers suffering from asbestosis were associated with lung cancer, ${ }^{1}$ a figure which had risen to nearly $50 \%$ of deaths in 1961-3.2 The increase was attributed partly to the increase in lung cancer in the general population but more especially to improvements in hygiene and medical surveillance so that workers developing asbestosis were tending to survive through the longer latent period for lung cancer.

In 1955 the first mortality study of asbestos workers had shown 11 deaths from lung cancer associated with asbestosis, and none ( 0.8 expected) without. $^{3}$ Lung cancer in asbestos workers in the United Kingdom was made a prescribed disease when (but only when) it was accompanied by asbestosis, and there was optimism that if asbestosis were eliminated the excess lung cancer risk would disappear. The 1960s brought the membrane filter method of fibre counting, and with it the first calculation of dose-response in asbestosis. ${ }^{4}$

In the next decade several mortality studies of asbestos workers were published with estimates of dust concentrations to which they had been exposed; dose-response calculations proliferated and epidemiology relegated pathology to the background. Many studies suggested a linear relation between lung cancer and cumulative exposure to asbestos, expressed as $\mathrm{f} / \mathrm{cc}$ years or an equivalent. Because of the long latent period between first exposure and the appearance of disease the relation was unavoidably based on the high exposures of past years. But whereas the evidence related to the effects of high doses of asbestos, extrapolations were made to estimate the effects of exposure to the much lower dust concentrations in contemporary factories, and then to the minute exposures found in the environment. In the past few years these extrapolations, at first acknowledged as "a convenience"s that "might best serve to protect the public" have come to be accepted as representing scientific fact. A review of the evidence therefore seems desirable. In his brief review in 1980 Sluis-Cremer was concerned mainly with evidence from pathology, animal experiments, and radiology, ${ }^{7}$ and I will begin with these topics before considering epidemiological issues.

Two characteristics of lung cancer in asbestos workers have been claimed. Firstly, some have shown that the normal preponderance of tumours in the upper over the lower lobes is reversed. ${ }^{7-12}$ Because the interstitial fibrosis of asbestosis normally begins in the lower lobes, it is suggested that this may indicate an aetiological connection. Secondly, several series have shown an increased incidence of adenocarcinomas over other types, ${ }^{101113}$ though not always statistically significant, ${ }^{9}$ and both Whitwell $e t$ $a l,{ }^{10}$ and Newhouse $e t a l^{14}$ have shown an increased proportion where asbestosis is also present compared with when it is absent. In no series, however, is the association so pronounced as to suggest that the asbestos risk is associated with only one histological type, a finding which probably applies to other occupationally related carcinogens. ${ }^{15}$ Nevertheless, since in all series a proportion of lung cancers are to be expected from smoking independently of asbestos, and will therefore dilute the asbestos effect, even a small increase in one histological type cannot be ignored. This is particularly the case with adenocarcinoma, which is the cell variant bearing the least relation to smoking. ${ }^{16}$

Two explanations have been offered for the enhanced carcinogenesis: firstly, that asbestos fibres become trapped in the fibrotic areas, disrupting the normal clearance mechanisms and adsorbing and concentrating carcinogens from tobacco smoke and 
elsewhere. ${ }^{17}$ Asbestos fibres tend to accumulate preferentially in the peripheral regions of the lower lobes, ${ }^{18}$ the commonest site for adenocarcinomas. The alternative explanation is that areas of fibrotic scar tissue may become the focus of carcinogenesis as in other "scar cancers" known to occur in relation to tuberculosis and other lung lesions; these are commonly adenocarcinomas. ${ }^{19}$ Premalignant changes in the epithelium in areas of fibrosis have been reported $^{2021}$ and an increased risk of lung cancer occurs in non-smoking asbestotic patients. ${ }^{22}$ Finally, an important related observation is the high incidence of bronchial carcinoma in other fibrotic lung diseases unrelated to asbestos, such as cryptogenic fibrosing alveolitis and pulmonary systemic sclerosis. ${ }^{16}$ This has led to the suggestion that more than one aetiological mechanism may operate. ${ }^{23}$

In inhalation experiments with rats Wagner et al found a relation between the degree of asbestosis and the incidence of lung tumours. ${ }^{20}$ They also found that in a group of rats with brief exposure to asbestos, six tumours occurred in the 157 rats which did not develop asbestosis $(3.8 \%)$, an incidence no higher than the controls, whereas 11 tumours $(25 \%)$ were seen in the 44 rats with the same exposure which developed asbestosis. In another series of inhalation experiments in rats Davis et al found, in comparing different chrysotile samples that the fibrogenic and tumorigenic effects were closely correlated. ${ }^{2425}$ This relation was confirmed in further inhalation experiments using a specially prepared sample of amosite fibres averaging only $2 \mu$ in length. This material produced no asbestosis, and no excess of tumours occurred. ${ }^{25} 26$

In an international study comparing inhalation effects of man made mineral fibres and chrysotile, only minimal fibrosis occurred with mmmf and no excess of neoplasms, whereas both occurred in the rats exposed to asbestos. ${ }^{27}$ The development of bronchoalveolar hyperplasia in areas of interstitial fibrosis leading to adenomatoid lesions with cellular metaplasia and subsequent neoplastic development has been shown. ${ }^{21}$

The apparent discrepancy between the carcinogenic potential of chrysotile-at least as great as that of amphiboles-in animal experiments compared with its lesser potential suggested by human experience has often received comment. It has been suggested that the discrepancy may be due to the greater tendency of chrysotile to separate into individual fibrils in the lungs and dissolve or fragment and be more easily cleared; in consequence, it may survive long enough to produce tumours in rats but not for the much longer period required for tumour induction in man. ${ }^{28}$ While this is an important observation, it must also be realised that mesotheliomas resulting from asbestos inhalation, as distinct from $\overline{\bar{\alpha}}$ implantation, are rare in rats. ${ }^{29}$ If the rat tumours are $\frac{\mathbb{D}}{2}$ almost all bronchial adenomas or carcinomas and if ? these are dependent on the degree of fibrosis present $\overrightarrow{\vec{F}}$ which in turn is related to the numbers of long fibrespresent in the dust clouds, some of the deductions $\subseteq$ from these experiments are seen to have been mis- $\frac{\bar{c}}{\bar{c}}$. placed.

In vitro experiments have also raised as many prob- $\varrho$ lems as they have solved. Asbestos is not mutagenic in के bacterial tests ${ }^{30}$ and does not yield covalent binding $\overrightarrow{0}$ electrophiles characteristic of initiators of the carcino- $\overrightarrow{\vec{H}}$ genic process. ${ }^{31}$ Asbestos fibres induce chromosome $\vec{\omega}$ aberrations in established cell lines ${ }^{32}$ but not sister $\stackrel{\circ}{\circ}$ chromatid exchanges, and the former effect may $\frac{\mathbb{D}}{3}$ merely result from the cytotoxicity of the fibres. ${ }^{33} \mathrm{On}$ the basis of in vitro studies it has been suggested that ${ }_{\omega}^{\omega}$ asbestos may be a complete carcinogen for meso- $t$ thelial cells but only a promoter for bronchial cells, $\overrightarrow{0}$ but the evidence is unconvincing. ${ }^{34}$ Several studies, $ᄋ$ on the other hand, have shown that asbestos may behave as a classical tumour promoter ${ }^{3536}$ requiring $\overrightarrow{3}$ previous interaction with the DNA of the target cell by an initiator before malignant change can take $\stackrel{\rho}{\mathcal{}}$ place. The carcinogens in cigarette smoke readily sug- $\overrightarrow{0}$ gest themselves as candidates for this role, but the $\infty$ high incidence of lung cancer in non-smokers suggests that an alternative mechanism is required. It is characteristic of promoters that their action must occur over a prolonged period; it may be reversible and $\bar{D}$ involves a threshold dose. Possibly these conditions $\frac{\mathscr{Q}}{\not}$

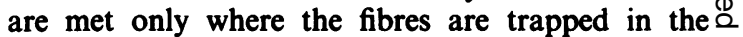
fibrotic lung tissue of asbestosis. In this connection it $\overrightarrow{\vec{O}}$ is noteworthy that in implantation experiments Stan- 3 ton et al commented on the abundant collagen in the preneoplastic pleural scars, ${ }^{37}$ and Suzuki and Kohyama on fibrosis as an important precondition $\bar{\partial}$ for the induction of neoplasms ${ }^{38}$; implantation of $\frac{\mathbb{}}{3}$ minerals that did not produce tumours was accom- panied by only mild and minimal fibrogenicity.

Bohlig et al in a study of radiographs of asbestosis $\delta$ in asbestos workers during life noted a lung cancer prevalence per thousand cases of eight in severe asbes- 0 tosis, one in minimal cases, and 0.4 in those without disease, the latter figure not exceeding that for the normal German population. ${ }^{39} \mathrm{~A}$ relation between the severity of asbestosis and the risk of death from lung $\sigma$ cancer was noted by Berry, ${ }^{40}$ though this may merely $N$ reflect increasing exposure. A similar conclusion was reached by Liddell and McDonald. ${ }^{41}$ In their cohort ${ }_{\sigma}^{\omega}$ of Canadian chrysotile miners who had had at least one chest radiograph taken while at work, 118 deaths from lung cancer occurred, an excess of 52 deaths. The SMR of the 49 men whose last radiograph was recorded as normal was 1.08 (and some of these would probably have gone on to develop an asbestos 
related abnormality in the years between this radiograph and death) whereas in those with "less than normal" radiographs the SMR was 3.5. The authors concluded "... most, but not necessarily all, cases of lung cancer attributable to chrysotile exposure in mining and milling probably have small parenchymal opacities before death. Presumably, histological evidence would be more sensitive."

A causal relation between lung cancer and asbestosis cannot be established by epidemiological means. On the other hand, there are certain prerequisites to be met if the relation is to be possible. It is generally accepted that there is a threshold dose below which clinical asbestosis will not appear (the Ontario Royal Commission estimated it to be about $25 \mathrm{f} / \mathrm{ml} \mathrm{years}^{42}$ ). If a causal relation were true a threshold should also exist below which no excess risk of lung cancer appears. Likewise, in studies of occupational exposure to asbestos in which asbestosis is not recorded, there should be no excess of deaths from lung cancer. It is fashionable to emphasise the linearity of the dose-response curve for lung cancer and the absence of any evidence for a threshold. Unfortunately, the inaccuracies in exposure estimates inevitably result in some smoothing of the doseresponse curve, so that a threshold response may appear linear. ${ }^{43} \mathrm{~A}$ numerical example will make this clear. Assume ex-employees from a factory are classified into four categories of cumulated exposure, $10,20,30$, and $40 \mathrm{f} / \mathrm{ml}$ years, and that a threshold for disease exists at $25 \mathrm{f} / \mathrm{ml}$ years, above which the incidence is $20 \%$. Assume also that exposures are misclassified to the extent that $25 \%$ of the individuals in any category really had exposures of the adjacent lower category and $25 \%$ of the adjacent higher category (this would represent quite a conservative estimate of error in real life); then instead of disease rates in the four categories being $0,0,20 \%, 20 \%$, the apparent response would be $0,5 \%, 15 \%, 20 \%$.

Despite the smoothing effect on the dose-response curve that results from imperfect exposure records, evidence of a threshold for an asbestos related increase in lung cancer risk does exist. Weill, reviewing the epidemiological evidence in 1979, said it suggested that the carcinogenic dose of asbestos may be higher than the fibrogenic dose. ${ }^{44}$ There is now considerable evidence to support his statement in series published since then in which asbestos exposure for each subject has been estimated individually in duration and intensity. Every one contains some evidence for a threshold. 45-56

In addition to those cohorts which provide evidence of a dose related increase in the risk of lung cancer several others have recently been reported with lower dose occupational exposures in which lung cancer rates have not been raised. These include the fric- tion materials factory of Berry and Newhouse ${ }^{53}$ and perhaps McDonald, ${ }^{54}$ asbestos-cement factories, ${ }^{57} 58$ dockyard, ${ }^{5960}$ and shipyard workers. ${ }^{61}$ The most fully documented of these is the Devonport naval dockyard $^{59}$ and in this, as in some of the other studies, confirmation that exposure to asbestos was not negligible is provided by the occurrence of mesotheliomas, pleural changes, and even some asbestosis.

There is therefore strong prima facie evidence that in occupational exposure to asbestos a threshold exists before the risk of lung cancer is increased.

Unfortunately, however, the interpretation of dose response figures at low levels of cumulative exposure is complicated by the higher mortality so frequently found in short term workers, and is discussed in some detail by Doll and Peto ${ }^{62}$ and McDonald et al $^{54}$ in relation to their own series. There is evidence that unskilled manual jobs, particularly in the dusty trades, attract a shifting population with an atypical lifestyle; they may have a higher death rate from violence $^{63-65}$ or suicide ${ }^{66}$ and a higher incidence of lung cancer ${ }^{64656768}$ after short exposures, and any attempt to relate excess risks to cumulative exposure must take account of this complication. It must also take into account that longer exposures at lower intensities may have proportionally greater carcinogenic effects than briefer, heavier exposures of equal cumulative totals. ${ }^{69}$ On the other hand, atypical mortality rates of short term workers cannot upset conclusions drawn from cohorts showing no increase in lung cancer rates, or case-control studies matched for duration of employment (though this was not done in the studies discussed).

It is frequently stated that a no-threshold dose response for asbestos related lung cancer should be assumed because it is a safer assumption when occupational hygiene standards are being set. 5642 While this may be true (although as a policy it is not without its side effects, such as panic removal which may create more hazard than it prevents), it is important that it should not inhibit scientific examination of the problem. The pressure to find substitutes for asbestos is resulting in the use of other respirable fibrous minerals such as wollastonite, sepiolite or attapulgite, or synthesised aluminosilicates, or organics such as aramids, of whose carcinogenic potential much less is known, and an understanding of the mechanism of asbestos induced lung cancer would help greatly in assessing the risk of new materials.

Epidemiology is probably too blunt an instrument to bring much furiher enlightenment, although on the data available a threshold seems probable. On the other hand, despite the disappointingly uninformed comment on the subject by Doll and Peto ${ }^{62}$ there is growing evidence from other disciplines, particularly 
from experimental pathology, that asbestos is not a complete carcinogen, ${ }^{70}$ and that neoplastic change may appear only in the wake of inflammation and subsequent fibrosis and adenosis. It seems probable, in Merewether's terminology, that it is not asbestos per se but asbestosis which prepares the soil for subsequent malignancy. But a definitive answer to this question is still urgently awaited.

\section{Department of Occupational Medicine, Brompton Hospital,} London SW3 6HP.

\section{References}

${ }^{1}$ Chief Inspector of Factories. Annual report for 1947. London: HMSO, 1949:79-81.

${ }^{2}$ Buchanan WD. Asbestosis and primary intrathoracic neoplasms. Ann NY Acad Sci 1965;132:507-18.

${ }^{3}$ Doll $\mathrm{R}$. Mortality from lung cancer in asbestos workers. $\mathrm{Br} \mathrm{J}$ Ind Med 1955;12:81-6.

${ }^{4}$ British Occupational Hygiene Society. Hygiene standards for chrysotile asbestos dust. Ann Occup Hyg 1968;11:47-69.

${ }^{5}$ McDonald JC, Liddell FDK, Gibbs GW, Eyssen GE, McDonald AD. Dust exposure and mortality in chrysotile mining 1910-75. Br J Ind Med 1980;37:11-24.

${ }^{6}$ Enterline PE. Extrapolation from occupational studies a substitute for environmental epidemiology. Environ Health Perspect 1981;42:39-44.

${ }^{7}$ Sluis-Cremer GK. The relationship between asbestosis and bronchial cancer. Chest 1980;78:380-1.

${ }^{8} \mathrm{Jacob}$ G, Anspach M. Pulmonary neoplasia among Dresden asbestos workers. Ann NY Acad Sci 1965;132:536-48.

${ }^{9}$ Kannersteing M, Churg J. The pathology of carcinoma of the lung associated with asbestos exposure. Cancer 1972;30:14-21.

${ }^{10}$ Whitwell F, Newhouse MD, Bennett DR. A study of the histological cell types of lung cancer in workers suffering from asbestosis. Br J Ind Med 1974;31:298-303.

${ }^{11}$ Warnock ML, Churg AM. Association of asbestos and bronchogenic carcinoma in a population with low asbestos exposure. Cancer 1975;35:1236-42.

${ }^{12}$ Smith PG. The pathology associated with asbestos. London Hospital Gazette 1967; LXX:3.

${ }^{13}$ Hasan FM, Nash G, Kazemi H. Asbestos exposure and related neoplasia. Am J Med 1978;65:649-54.

${ }^{14}$ Newhouse ML, Berry G, Wagner JC. Mortality of factory workers in east London 1933-80. Br J Ind Med 1985;42:4-11.

${ }^{15}$ Ives JC, Buffler PA, Greenberg SD. Environmental associations and histopathologic patterns of carcinoma of the lung: the challenge and dilemma in epidemiologic studies. Am Rev Respir Dis 1983;128:195-209.

${ }^{16}$ Turner-Warwick M. Immunology of the lung. London: Edward Arnold, 1978.

${ }^{17}$ Mossman BT, Eastman A, Landesman JM, Bresnick E. Effects of crocidolite and chrysotile asbestos on cellular uptake and metabolism of benzo(a)pyrene in hamster tracheal epithelial cells. Environ Health Perspect 1983;51:331-5.

${ }^{18}$ Craighead JE, Mossman BT. The pathogenesis of asbestos associated diseases. $N$ Engl J Med 1982;306:1446-55.

${ }^{19}$ Schmaehl DFK. Carcinogenic aspects of asbestos. In: Proceedings of the world symposium on asbestos. Montreal: Canadian Asbestos Information Centre, 1983:68-72.

${ }^{20}$ Wagner JC, Berry G, Timbrell V. Mesotheliomata in rats after inoculation with asbestos and other materials. $\mathrm{Br} \mathrm{J}$ Cancer 1973;28:173-85.

${ }^{21}$ Davis JMG, Bolton RE, Brown D, Tully HE. Experimental lesions in rats corresponding to advanced human asbestosis. Exptl $\mathrm{Mol}$ Pathol (in press).

${ }^{22}$ Berry G, Newhouse ML, Antonis P. Combined effect of asbestos and smoking on mortality from lung cancer and mesothelioma in factory workers. $\mathrm{Br} J$ Ind Med 1985;42:12-8.

${ }^{23}$ Becklake MR. Asbestos-related diseases of the lungs and pleura. Am Rev Respir Dis 1980;126:187-94.

${ }^{24}$ Davis JMG, Beckett ST, Bolton RE, Collings PF, Middleton AP. Mass and number of fibres in the pathogenesis of asbestosrelated lung disease in rats. $\mathrm{Br} J$ Cancer 1978;37:673-88.

${ }^{25}$ Davis JMG, Addison J, Bolton RE, Donaldson K, Jones AD. Inhalation and injection studies in rats using dust samples from chrysotile asbestos prepared by a wet dispersion process. $\mathrm{Br} J$ Exp Pathol (in press).

${ }^{26}$ Davis JMG, Addison J, Bolton RE, Donaldson K, Jones AD, Smith T. The pathogenicity of long versus short fibre samples of amosite asbestos administered to rats by inhalation and intraperitoneal injection. Br J Exp Pathol (in press).

${ }^{27}$ McConnell EE, Wagner JC, Skidmore JW, Moore JA. A comparative study of the fibrogenic and carcinogenic effects of UICC Canadian chrysotile B asbestos and glass microfibre (JM 100). Biological effects of man-made mineral fibres. Copenhagen: World Health Organisation, 1984:234-52.

${ }^{28}$ Davis JMG. Carcinogenic effect of mineral fibres in inhalation studies. In: Colloquium on fibrous dusts 1982. Dusseldorf: VDI Kommission Reinhaltung der Luft, 1983:241-6. (VDI report No 475.)

${ }^{29}$ Wagner JC. Health hazards of substitutes. In: Proceedings of the world symposium on asbestos. Montreal: Canadian Asbestos Information Centre, 1983:244-51.

${ }^{30}$ Light WG, Wei ET. Surface charge and a molecular basis for asbestos toxicity. In: Brown RC, Gormley IP, Chamberlain M, Davies $R$, eds. The in vitro effects of mineral dusts. London: Academic Press Inc 1980:139-45.

${ }^{31}$ Miller EC, Miller JA. Mechanisms of chemical carcinogenesis. Cancer 1981:47:1055-64.

${ }^{32}$ Brown RC, Chamberlain M, Davies R, Gaffen J, Skidmore JW. In vitro biological effects of glass fibres. $J$ Environ Pathol Toxicol 1979;2:1369-83.

${ }^{33}$ Price-Jones MJ, Gubbings G, Chamberlain M. The genetic effects of crocidolite asbestos; comparison of chromosome abnormalities and sister chromatid exchanges. Mutat Res 1980;79:331-6.

${ }^{34}$ Mossman B, Light W, Wei E. Asbestos: mechanisms of toxicity and carcinogenicity in the respiratory tract. Ann Rev Pharmacol Toxicol 1983;23:595-615.

${ }^{35}$ Topping DC, Nettlesheim P. Two-stage carcinogenesis studies with asbestos in Fischer 344 rats. JNCI 1980;65:627-30.

${ }^{36}$ National Research Council. Asbestiform fibres; non-occupational health risks. Washington DC: NRC, 1984.

${ }^{37}$ Stanton MF, Layard M, Tegeris A, et al. Relation of particle dimension to carcinogenicity in amphibole asbestoses and other fibrous minerals. JNCI 1981;67:965-75.

${ }^{38}$ Suzuki Y, Kohyama N. Malignant mesothelioma induced by $O$ asbestos and zeolite in the mouse peritoneal cavity. Environ Res 1984;35:277-92.

${ }^{39}$ Bohlig H, Jacob G, Muller H. Die asbestose der lunger. Stuttgart: Georg Thieme Verlag, 1960:60.

${ }^{40}$ Berry G. Mortality of workers certified by pneumoconiosis medi- $\Omega$ cal panels as having asbestosis. Br J Ind Med 1981;38:130-7.

${ }^{41}$ Liddell FDK, McDonald JC. Radiological findings as predictors of mortality in Quebec asbestos workers. Br J Ind Med $\omega$ 1980;37:257-67.

42 Royal Commission on matters of health and safety arising from the use of asbestos in Ontario. Toronto: Ontario Ministry of the Attorney General, 1984.

${ }^{43}$ Crump KS. Evidence to OSHA hearing on a proposed revision of the asbestos standard 1984.

${ }^{44}$ Weill H. Asbestos-a summing up. In: Wagner JC, ed. Biological effects of mineral fibres. Lyon: IARC, 1980:868. (IARC scientific $\mathbb{D}$ publication No 30.) 
${ }^{45}$ McDonald JC. Mineral fibres and cancer. Ann Acad Med Singapore 1984;13:345-52.

${ }^{46}$ Peto J, Doll R, Herman C, Binns R, Goffe T, Clayton R. Relationship of mortality to measures of environmental pollution in an asbestos textile factory. Ann Occup Hyg 1985;29:305-55.

${ }^{47}$ Liddell FDK, McDonald JC, Thomas DC. Methods of cohort analysis: appraisal by application to asbestos mining. Journal of the Royal Statistical Society 1977;140:469-91.

${ }^{48}$ McDonald JC, Liddell FDK, Gibbs GW, Eyssen GE, McDonald AD. Dust exposure and mortality in chrysotile mining, 1910-75. Br J Ind Med 1980;37:11-24.

${ }^{49}$ Enterline P, De Coufle P, Henderson V. Respiratory cancer in relation to occupational exposures among retired asbestos workers. Br J Ind Med 1973;30:162-6.

${ }^{50}$ Hughes J, Weill H. Lung cancer risk associated with manufacture of asbestos-cement products. In: Wagner JC, ed. Biological effects of mineral fibres. Lyon: International Agency for Research on Cancer, 1980:627-35.

${ }^{51}$ McDonald AD, Fry JS, Woolley AJ, McDonald JC. Dust exposure and mortality in an American chrysotile textile plant. Br J Ind Med 1983;40:361-7.

${ }^{52}$ McDonald AD, Fry JS, Woolley AJ, McDonald JC. Dust exposure and mortality in an American factory using chrysotile, amosite, and crocidolite in mainly textile manufacture. $\mathrm{Br} \mathrm{J}$ Ind Med 1983;40:368-74.

${ }^{33}$ Berry G, Newhouse ML. Mortality of workers manufacturing friction materials using asbestos. Br J Ind Med 1983;40:1-7.

${ }^{54}$ McDonald AD, Fry JS, Woolley AJ, McDonald JC. Dust exposure and mortality in an American chrysotile asbestos friction products plant. $\mathrm{Br} J$ Ind Med 1984;41:151-7.

${ }^{55}$ Seidman H, Selikoff IJ, Hammond EC. Short-term asbestos work exposure and long-term observation. Ann NY Acad Sci 1979;330:61-89.

${ }^{36}$ Acheson ED, Gardner MJ. Asbestos: the control limit for asbestos. London: HMSO, 1983.

${ }^{57}$ Thomas HF, Benjamin IT, Elwood PC, Sweetnam PM. Further follow up study of workers from an asbestos cement factory. $\mathrm{Br}$ $J$ Ind Med 1982;39:273-6.

${ }^{58}$ Hodgson JT, Jones RD. Mortality of asbestos workers in England and Wales 1971-81. Br J Ind Med (in press).

${ }^{59}$ Rossiter CE, Coles RM. HM Dockyard, Devonport: 1947 mortality study. In: Wagner JC, ed. Biological effects of mineral fibres. Lyon: International Agency for Research on Cancer, 1980:713-21. (IARC scientific publication No 30.)

${ }^{60}$ Farebrother MJB, Heller RF, O'Brien I, Azzoparde A, Telfa TP, Young M. Occupation and lung cancer in a naval dockyard area. (Abstract). Thorax 1983;38:225.

${ }^{61}$ Newhouse ML, Oakes D, Woolley AJ. Mortality of welders and other craftsmen at a shipyard in NE England. Br J Ind Med 1985;42:406-10.

${ }^{62}$ Doll R, Peto J. Effects on health of exposure to asbestos. London: HMSO, 1985.

${ }^{63}$ Shannon HS. A mortality study of 11,500 nickel workers. JNCI 1984;73:1251-8.

${ }^{64}$ Saracci R, Simonato L, Acheson ED, et al. Mortality and incidence of cancer of workers in the man made vitreous fibres producing industry: an international investigation at 13 European plants. Br J Ind Med 1984;41:425-36.

${ }^{65}$ Ohlson CG, Hogstedt C. Lung cancer among asbestos cement workers. A Swedish cohort study and a review. Br J Ind Med 1985; 42:397-402.

${ }^{66}$ Acheson ED, Gardner MJ, Winter PD, Bennett C. Cancer in a factory using amosite asbestos. Int J Epidemiol 1984;13:3-10.

${ }^{67}$ Fox AJ, Collier PF. Low mortality rates in industrial cohort studies due to selection for work and survival in the industry. $\mathrm{Br} J$ Prev Soc Med 1976;30:225-30.

${ }^{68}$ Davies JM. Lung cancer mortality among workers making lead chromate and zinc chromate pigments at three English factories. Br J Ind Med 1984;41:158-69.

${ }^{69}$ Doll R. Occupational cancer: problems in interpreting the human evidence. Ann Occup Hyg 1983;28:291-305.

${ }^{70}$ Boyland E. Tumour initiators, promoters and complete carcinogens. $\mathrm{Br} J$ Ind Med 1985;42:716-8.

\section{Destruction of manuscripts}

From 1 July 1985 articles submitted for publication will not be returned. Authors whose papers are rejected will be advised of the decision and the manuscripts will be kept under security for three months to deal with any inquiries and then destroyed. 